\title{
Effects of the open lung concept following ARDSnet ventilation in patients with early ARDS
}

\author{
Vivian Rotman ${ }^{1 *}$, Alysson Roncally Carvalho ${ }^{2}$, Rosana Souza Rodrigues ${ }^{3,4}$, Denise Machado Medeiros ${ }^{5}$, \\ Eduardo Costa Pinto ${ }^{6}$, Fernando Augusto Bozza ${ }^{4,5}$ and Carlos Roberto Ribeiro Carvalho ${ }^{7}$
}

\begin{abstract}
Background: Ventilation with low tidal volume $\left(V_{T}\right)$ is well recognized as a protective approach to patients with acute respiratory distress syndrome (ARDS), but the optimal level of positive end-expiratory pressure (PEEP) remains uncertain. This study aims to evaluate two protective ventilatory strategies sequentially applied in patients with early ARDS.

Methods: In this prospective cohort study, fifteen patients were ventilated during $24 \mathrm{~h}$ with positive end-expiratory pressure (PEEP) adjusted according to the ARDSnet low-PEEP table (ARDSnet-24 h). During the next $24 \mathrm{~h}$, nine patients with PaO2/FIO2 ratio below $350 \mathrm{mmHg}$ were ventilated with PEEP titrated according to the Open Lung Concept protocol (ARDSnet $+\mathrm{OLC}$ ). In the other six patients, regardless of their PaO2/FIO2 ratio, the ARDSnet remained for a further $24 \mathrm{~h}$ (ARDSnet-48 h). Ventilatory variables, arterial blood-gas and cytokine were obtained at baseline, 24 and $48 \mathrm{~h}$. Additionally, whole-lung-computed tomography was acquired at 24 and $48 \mathrm{~h}$.

Results: A sustained improvement in $\mathrm{PaO} 2 / \mathrm{FIO} 2$ ratio $(P=0.008)$ with a decrease in collapsed regions $(P=0.008)$ was observed in the ARDSnet + OLC group compared with the ARDSnet- $24 \mathrm{~h}$ group. A reduction in IL-6 in plasma $(P<0.02)$ was observed throughout the protocol in the ARDSnet + OLC group. Compared with the ARDSnet-48 $\mathrm{h}$ group, the ARDSnet + OLC presented smaller amounts of collapsed areas $(P=0.018)$ without significant differences in hyperinflated regions and in driving and plateau pressures.
\end{abstract}

Conclusions: In this set of patients with early ARDS, mechanical ventilation with an individually tailored PEEP sustained improved pulmonary function with better aeration, without significant increase in hyperinflated areas".

Trial registration: Brazilian Clinical Trials Registry (ReBec). RBR-5zm9pr. 04th November 2015

Keywords: Lung -adult respiratory distress syndrome, Measurement techniques - tomography, Ventilation - effects

\section{Background}

Ventilatory strategies employing high tidal volumes $\left(\mathrm{V}_{\mathrm{T}}\right)$ have been shown to induce lung injury and are associated with increased mortality in patients with Acute Respiratory Distress Syndrome (ARDS) $[1,2]$. Although the reduction in $\mathrm{V}_{\mathrm{T}}$ is well recognized as a protective approach $[3,4]$, the optimal level of positive endexpiratory pressure (PEEP) remains uncertain [5-7].

\footnotetext{
* Correspondence: vrotman@gmail.com

This study was performed at Copa D'Or Hospital, Rio de Janeiro, Brazil. ${ }^{1}$ Internal Medicine Department, Federal University of Rio de Janeiro, Rua Reseda, 23/401, Rio de Janeiro 22471-230, Brazil

Full list of author information is available at the end of the article
}

Large trials comparing high and low levels of PEEP with low $\mathrm{V}_{\mathrm{T}}$ failed to show differences in mortality [8-10], although an improvement in oxygenation was generally observed in the higher PEEP groups $[9,10]$. This improvement, however, may be transitory and/or have no impact on mortality. The potential benefits of high levels of PEEP seem to be dependent upon the severity of pulmonary injury $[6,7]$ and may reduce mortality in patients with persistent and severe hypoxemia, preventing lung collapse and further hypoxia $[6,11]$.

Although it has already been shown that recruitment maneuvers associated with PEEP titration determine improvement in lung compliance and oxygenation, and 
reduction in cytokines levels, these analyses were mainly done in a transversal way. In the research that made a prolonged analysis (until $40 \mathrm{~h}$ ), there was no tomographic evaluation. A prolonged longitudinal conjoint analysis of lung aeration by computed tomography (CT) scan and cytokines is lacking [12,13].

In the present study, we evaluated the effects on pulmonary function, aeration and inflammatory response of two protective ventilatory strategies with low and high levels of PEEP individually titrated and sequentially applied in patients with early-established ARDS. Our analysis focused on the effects of each ventilatory strategy regarding oxygenation, lung mechanics, pulmonary aeration and inflammation after $24 \mathrm{~h}$ of mechanical ventilation. Our hypothesis is that individually titrated PEEP levels add benefits to protective ventilatory strategies.

\section{Methods}

\section{Patient enrollment}

The present study was conducted at the Hospital Copa D'Or, a tertiary care hospital located in Rio de Janeiro, Brazil. The Hospital Institutional Review Board (IRB) approved the study protocol (number: HCB027/05) and written informed consent (including the permission to publish indirect identifiers) was obtained from all patients or next-of-kin relatives. Fifteen patients with clinical ARDS diagnosis [14] with $\mathrm{PaO}_{2} / \mathrm{FIO}_{2}$ ratios lower than $300 \mathrm{mmHg}$ after $30 \mathrm{~min}$ of mechanical ventilation with a PEEP of $5 \mathrm{cmH}_{2} \mathrm{O}$, an $\mathrm{FIO}_{2}$ of 1.0 and a $\mathrm{V}_{\mathrm{T}}$ ranging from 8 to $10 \mathrm{~mL} / \mathrm{kg}$ of ideal body weight (IBW), along with hemodynamically stable parameters (mean arterial pressures higher than $65 \mathrm{mmHg}$ and arterial lactates lower than $3 \mathrm{mmoL} / \mathrm{L}$ ) over the preceding $6 \mathrm{~h}$ [15], were enrolled in the study.

Patients were excluded if more than $48 \mathrm{~h}$ had elapsed since their diagnosis of ARDS, or if any of the following clinical conditions were identified: pneumothorax, pneumomediastinum, bronchopleural fistula, subpleural blebs, increased intracranial pressure, a body weight greater than $140 \mathrm{~kg}$, pregnancy, or a coexistent disease with an expected 6-month mortality risk exceeding $50 \%$.

\section{Experimental protocol}

Figure 1 summarizes the experimental protocol. Briefly, all patients were kept sedated and lying in a supine position while being ventilated (SERVOi, MAQUET, Sweden) with the bed elevated at $30^{\circ}$. Baseline data, including ventilatory variables and arterial blood samples for gas and cytokine analyses were obtained just after patient inclusion. Thereafter, all patients were ventilated according to the ARDSnetwork low-PEEP table [2], with a $\mathrm{V}_{\mathrm{T}}$ of $6 \mathrm{~mL} / \mathrm{kg}$ (ranging from 4 to $8 \mathrm{~mL} / \mathrm{kg}$ ), and plateau pressure maintained below $30 \mathrm{cmH}_{2} \mathrm{O}$ over the next $24 \mathrm{~h}$. After this period, respiratory variables and arterial blood samples were collected, and patients were transported to the Radiology Department for CT-scan imaging, in SERVOi, without ventilator disconnection (ARDSnet-24 h). After $24 \mathrm{~h}$ of ventilation according to ARDSnet, the first nine patients with the $\mathrm{PaO}_{2} / \mathrm{FIO}_{2}$ ratio below $350 \mathrm{mmHg}$ were ventilated according to the Open Lung Concept (OLC) for the next $24 \mathrm{~h}$ (ARDSnet + OLC). The next six patients, regardless of their $\mathrm{PaO}_{2} / \mathrm{FIO}_{2}$ ratios, served as controls and remained on the ARDSnet-low PEEP table protocol for an additional $24 \mathrm{~h}$ (ARDSnet-48 h). At the end of this period, arterial blood samples, respiratory variables and a new whole-lung CT-scan were acquired.

\section{Open lung concept protocol \\ Recruitment maneuver (RM)}

In the OLC protocol, an RM was performed in Pressure Controlled Ventilation (PCV): driving pressure of 20 $\mathrm{cmH}_{2} \mathrm{O}$; inspiratory time of $3 \mathrm{~s}$; inspiratory to expiratory

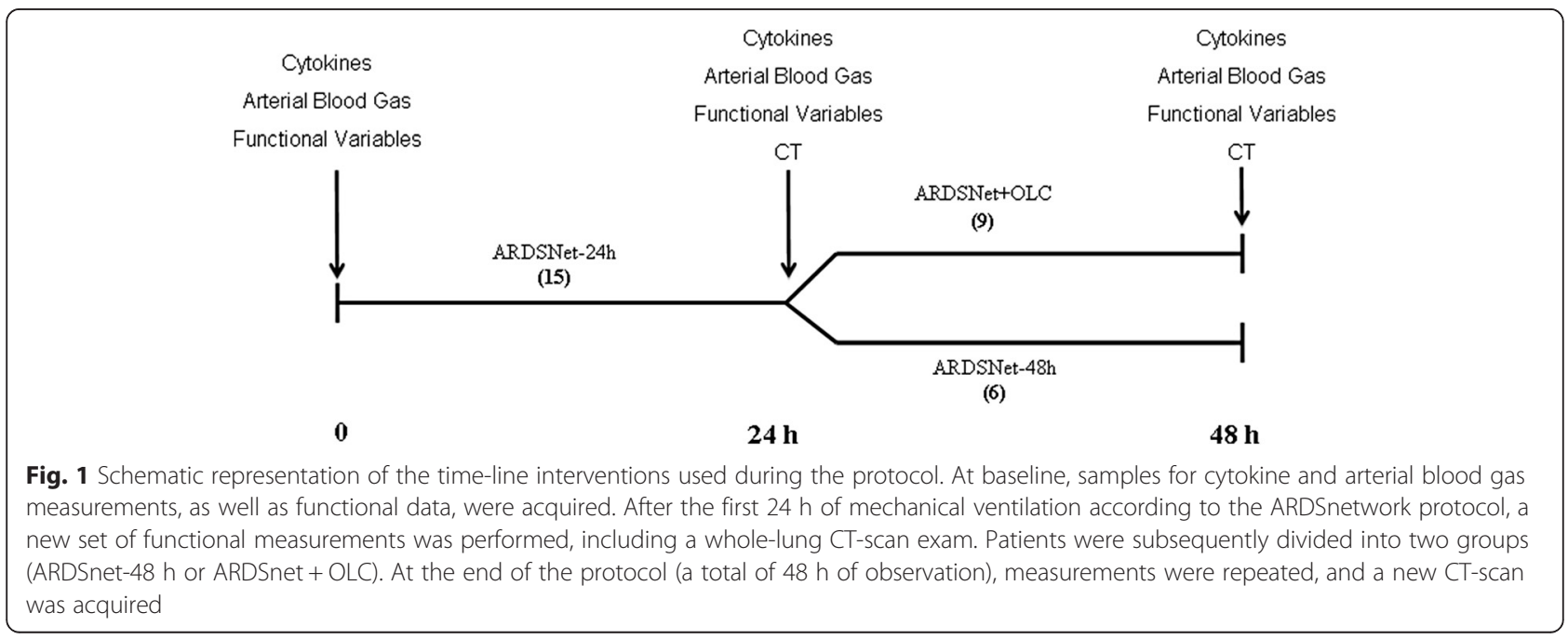


ratio (I:E) of $1: 1 ; \mathrm{FIO}_{2}$ of 1.0 and PEEP sequentially increased to 25 and $30 \mathrm{cmH}_{2} \mathrm{O}$; two minutes per step. Thereafter, driving pressure was adjusted to keep a $\mathrm{V}_{\mathrm{T}}$ of $6 \mathrm{~mL} / \mathrm{kg}$ (IBW) and respiratory rate (RR) was increased to $15 \mathrm{bpm}$ with I:E ratio of 1:2-1:3 [14].

\section{PEEP titration}

Immediately after the RM, PEEP was adjusted to 17 $\mathrm{cmH}_{2} \mathrm{O}$ while keeping all other parameters constant for at least $20 \mathrm{~min}$ [16]. After this period, if the $\mathrm{PaO}_{2} / \mathrm{FIO}_{2}$ ratio was lower than $350 \mathrm{mmHg}$ [16], the last step of the $\mathrm{RM}$ (driving pressure of $20 \mathrm{cmH}_{2} \mathrm{O}$ and PEEP of 30 $\mathrm{cmH}_{2} \mathrm{O}$ ) was repeated. Thereafter the driving pressure was adjusted to provide a $\mathrm{V}_{\mathrm{T}}$ of $6 \mathrm{~mL} / \mathrm{kg}$ and the PEEP was adjusted to $19 \mathrm{cmH}_{2} \mathrm{O}$. Twenty minutes afterwards, a new blood sample was collected and if the $\mathrm{PaO}_{2} / \mathrm{FIO}_{2}$ ratio remained below $350 \mathrm{mmHg}$, the last step of the $\mathrm{RM}$ was repeated and after driving pressure adjustment PEEP was set at $21 \mathrm{cmH}_{2} \mathrm{O}$. Twenty minutes later, if the $\mathrm{PaO}_{2} / \mathrm{FIO}_{2}$ ratio was still lower than $350 \mathrm{mmHg}$, the PEEP associated with the highest $\mathrm{PaO}_{2} / \mathrm{FIO}_{2}$ ratio was selected.

During the OLC protocol, the driving pressure was continuously adjusted to keep Pplat below $30 \mathrm{cmH}_{2} \mathrm{O}$ and the $\mathrm{pH}$ higher than 7.2 , with the respiratory rate ranging from 15 to $20 / \mathrm{min}$. No further RMs were performed throughout the OLC protocol.

\section{CT acquisition and analysis}

Whole-lung helical CT-scan images were acquired during an expiratory breath-hold maneuver (6s) at 24 and $48 \mathrm{~h}$ of the protocol. During CT acquisitions, patients were sedated, paralyzed and ventilated with an $\mathrm{FIO}_{2}$ of 1.0 according to the respective ventilatory strategy.

CT images were acquired on one of three scanners: a Light Speed QX/i, a Light Speed Pro 16, or a Light Speed VCT (GE Medical Systems, Milwaukee, WI). CT scans were obtained sequentially using the following parameters: $0.8 \mathrm{~s}$ (Light Speed QX/i) or $0.5 \mathrm{~s}$ (Light Speed Pro 16 and Light Speed VCT) axial time rotations, $1.25-\mathrm{mm}$ section reconstructions, 5-mm intervals, 120 kVp, 150-250 mA (Light Speed QX/i) or mA adjustment (Light Speed Pro 16 and Light Speed VCT), and a $512 \times 512$ pixel matrix.

Image analyses were performed with a purpose-built routine written in MatLab (Mathworks) by one of the authors (ARC). The region of interest (ROI) was manually selected in each slice by taking the inner contour of the thorax but excluding the chest wall, mediastinum, pleural effusions and regions presenting partial volume effects. For each ROI, the total volume of hyperaerated $(-1,000$ to -900 Hounsfield units-HU), normally $(-900$ to $-500 \mathrm{HU})$, poorly ( -500 to $-100 \mathrm{HU})$ and non-aerated
$(-100$ to $+100 \mathrm{HU})$ regions were computed and color mapped [17]. Additionally, the total mass of each compartment was calculated [16, 18]. From the total lung volume, $3 \mathrm{D}$ reconstructions were created by masking the lung boundary as well as each aeration compartment.

\section{Cytokine analysis}

Arterial blood samples, collected at Baseline, 24 and $48 \mathrm{~h}$ during the protocol, were centrifuged and the plasma stored at $-70{ }^{\circ} \mathrm{C}$ for subsequent cytokine analysis.

Interleukins 6 and 8 (IL-6 and -8) were measured using commercially available ELISA kits in accordance with the manufacturer's instructions (R\&D Systems, Minneapolis, EUA).

\section{Statistical analysis}

Data are presented as median, first and third quartiles. Differences were considered significant if $P<0.05$. The temporal effects related to changes in aeration, ventilatory variables, and cytokine analyses in each group were compared with the Wilcoxon sign rank test for paired samples. Comparisons between groups (ARDSnet-48 h and ARDSnet + OLC) were performed with the MannWhitney test using the SPSS statistical package (Version 16.0, SPSS, Inc.).

\section{Results}

Baseline parameters are presented in Table 1. The majority of the patients included had pneumonia, and none had trauma. Both groups were comparable regarding age, Apache II, SOFA, time of mechanical ventilation, respiratory system compliance and $\mathrm{PaO}_{2} / \mathrm{FIO}_{2}$ ratio (Table 1). According to the Berlin Definition [14] ARDS was classified as mild in 10 patients (6 in ARDSnet + OLC and 4 in ARDSnet-48 h), moderate in 4 ( 2 in each group) and severe in one patient (in ARDSnet + OLC group). Outcomes are presented in Table 2.

\section{Gas exchange, hemodynamic and respiratory variables} Respiratory variables are presented in Table 3. A significant increase in $\mathrm{PaCO}_{2}(P=0.002)$ and a reduction in $\mathrm{pH}$ $(P=0.017)$ were observed after the first $24 \mathrm{~h}$ of ARDSnet strategy compared with Baseline. The institution of the OLC led to a significant and sustained improvement in the $\mathrm{PaO}_{2} / \mathrm{FIO}_{2}$ ratio $(P=0.008)$ with increased respiratory system compliance $(P=0.04)$ compared with Baseline. No significant difference was observed in $\mathrm{PaCO}_{2}(P=0.26)$, driving or plateau pressures $(P=0.17$ and 0.05 , respectively). No significant improvement in oxygenation was observed in the ARDSnet-48 $\mathrm{h}$ group. The use of vasopressors and MAP levels were comparable among groups, although a lower fluid balance was observed in the OLC group $(P=0.04)$. 
Table 1 Baseline characteristics of the patients

\begin{tabular}{|c|c|c|c|c|c|c|c|c|}
\hline Group & Age & Gender & Apache II & Basal SOFA & Underlying disease & $\begin{array}{l}\text { Time on MV at } \\
\text { baseline (hours) }\end{array}$ & $\mathrm{Crs}\left(\mathrm{mLcmH} \mathrm{H}_{2} \mathrm{O}\right)$ & $\mathrm{PaO}_{2} / \mathrm{FIO}_{2}$ \\
\hline ARDSnet + OLC & 71 & $\mathrm{~F}$ & 23 & 7 & Pneumonia & 12 & 34 & 217 \\
\hline ARDSnet + OLC & 76 & M & 17 & 7 & Pneumonia & 11 & 20 & 179 \\
\hline ARDSnet + OLC & 63 & M & 16 & 8 & Pneumonia & 24 & 33 & 250 \\
\hline ARDSnet + OLC & 73 & M & 18 & 8 & Pneumonia & 22 & 41 & 246 \\
\hline ARDSnet + OLC & 62 & $\mathrm{~F}$ & 11 & 7 & Pneumonia/Acute Pancreatitis & 7 & 25 & 226 \\
\hline ARDSnet + OLC & 31 & M & 25 & 5 & Pneumonia & 48 & 30 & 220 \\
\hline ARDSnet + OLC & 50 & $\mathrm{~F}$ & 22 & 7 & Pneumonia & 7 & 58 & 229 \\
\hline ARDSnet + OLC & 79 & M & 20 & 5 & Pneumonia & 24 & 32 & 78 \\
\hline ARDSnet + OLC & 46 & $\mathrm{~F}$ & 32 & 11 & Multiple transfusions & 24 & 25 & 171 \\
\hline Median (1QR) & $63(48-75)$ & & $20(17-24)$ & $5(4-7)$ & & $22(9-24)$ & $32(25-37)$ & $220(175-237)$ \\
\hline ARDSnet-48 h & 24 & M & 17 & 8 & Pneumonia & 6 & 45 & 201 \\
\hline ARDSnet-48 h & 66 & M & 10 & 4 & Urinary sepsis & 48 & 51 & 278 \\
\hline ARDSnet-48 h & 88 & $\mathrm{~F}$ & 19 & 6 & Pneumonia & 24 & 40 & 125 \\
\hline ARDSnet-48 h & 41 & M & 16 & 4 & Pneumonia & 48 & 53 & 279 \\
\hline ARDSnet-48 h & 88 & M & 19 & 7 & Pneumonia & 13 & 35 & 266 \\
\hline ARDSnet-48 h & 66 & M & 15 & 7 & Pneumonia & 16 & 28 & 144 \\
\hline Median (1QR) & $66(37-88)$ & & $17(14-19)$ & $7(5-8)$ & & $20(11-48)$ & $43(33-52)$ & 233 (139-278) \\
\hline Overal Median (1QR) & $63(48-75)$ & & $20(17-24)$ & $7(6-8)$ & & $15(8-28)$ & $32(25-37)$ & $220(175-237)$ \\
\hline
\end{tabular}

$M$ male, $F$ female, Apache, Acute Physiology and Chronic Health Evaluation II score, SOFA Sequential Organ Failure Assessment, $M V$ mechanical ventilation, $\mathrm{Crs}$ respiratory system compliance, $\mathrm{PaO}_{2}, / \mathrm{FIO}_{2}$ arterial pressure of oxygen/inspiratory fraction of oxygen ratio

Table 2 Patients outcomes

\begin{tabular}{|c|c|c|c|c|c|c|c|}
\hline Group & Barotrauma & Liberation of MV & ICU death & Hospital death & Day of death & Days of ICU & Days of hospitalization \\
\hline ARDSNet + OLC & No & Yes & No & No & & 10 & 18 \\
\hline ARDSNet + OLC & No & Yes & No & No & & 36 & 53 \\
\hline ARDSNet + OLC & No & No & Yes & Yes & 15 & 16 & 16 \\
\hline ARDSNet + OLC & No & Yes & No & No & & 28 & 75 \\
\hline ARDSNet + OLC & No & Yes & No & No & & 19 & 195 \\
\hline ARDSNet + OLC & No & Yes & No & No & & 40 & 59 \\
\hline ARDSNet + OLC & Yes & No & Yes & Yes & 106 & 107 & 107 \\
\hline ARDSNet + OLC & No & No & Yes & Yes & 17 & 31 & 31 \\
\hline ARDSNet + OLC & No & Yes & Yes & Yes & 13 & 14 & 14 \\
\hline ARDSNet & No & Yes & No & No & & 4 & 10 \\
\hline ARDSNet & No & Yes & No & No & & 12 & 14 \\
\hline ARDSNet & No & No & Yes & Yes & 0 & 2 & 3 \\
\hline ARDSNet & No & Yes & No & No & & 15 & 38 \\
\hline ARDSNet & No & Yes & No & No & & 13 & 30 \\
\hline \multirow[t]{2}{*}{ ARDSNet } & No & No & Yes & Yes & 14 & 17 & 17 \\
\hline & & & & & & $28(15-38)$ & 53 (17-91) \\
\hline
\end{tabular}


Table 3 Respiratory variables

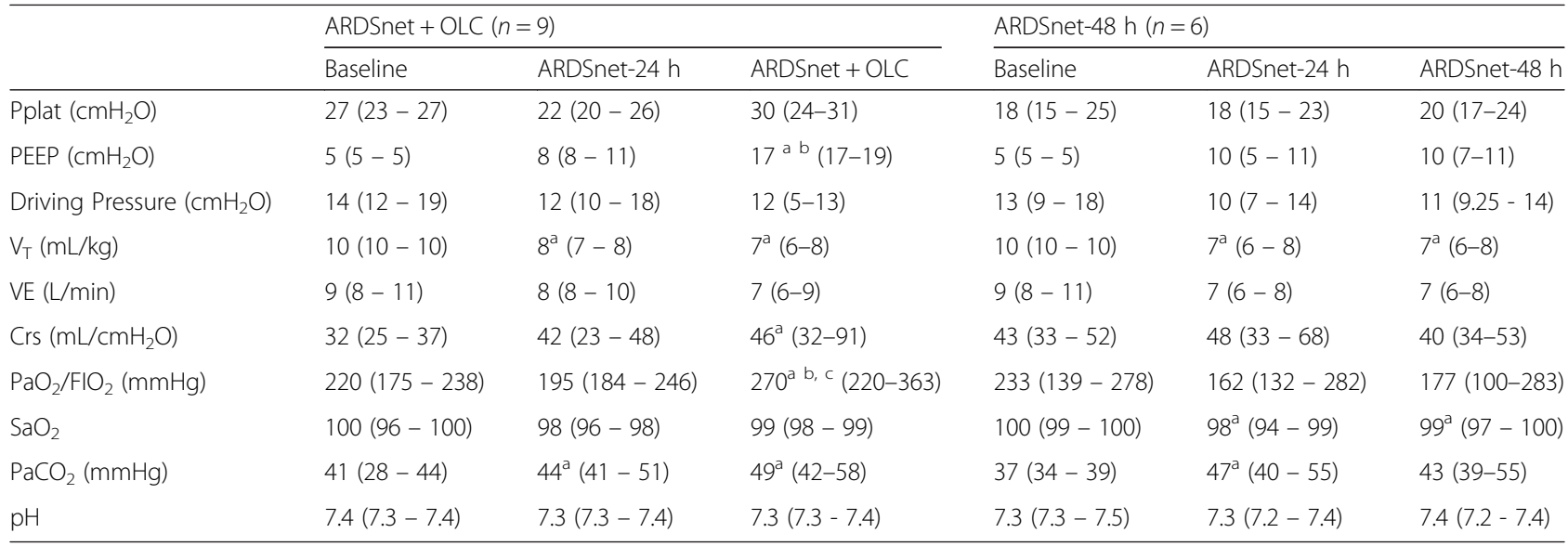

Pplat plateau pressure of the respiratory system, Driving Pressure inspiratory pressure above PEEP in Pressure Controlled Ventilation Mode

$V_{T}$ tidal volume in $\mathrm{mL} / \mathrm{kg}$ of predicted body weight, $V E$ minute ventilation, $P E E P$ positive end-expiratory pressure, $P a \mathrm{O}_{2} / \mathrm{FIO} \mathrm{O}_{2}$ arterial pressure of oxygen/inspiratory fraction of oxygen ratio, $\mathrm{Cr}$ respiratory system compliance, $\mathrm{PaCO}_{2}$ arterial pressure of carbon dioxide, $\mathrm{SaO}_{2}$ arterial blood saturation. Data is presented as median, first and third quartiles

${ }^{\text {a }}$ Significant differences compared to Baseline

bignificant differences compared to ARDSnet-24 h

'Significant differences compared to ARDSnet-48 h

No hemodynamic instability was observed during recruitment. During PEEP titration, three patients did not reach a $\mathrm{PaO}_{2} / \mathrm{FIO}_{2}$ ratio higher than $350 \mathrm{mmHg}$, even at the highest PEEP level employed $\left(21 \mathrm{cmH}_{2} \mathrm{O}\right)$. The PEEP was then adjusted according to the maximal oxygenation level reached at $19 \mathrm{cmH}_{2} \mathrm{O}$ in 2 cases and $17 \mathrm{cmH}_{2} \mathrm{O}$ in the other case.

\section{Quantitative and qualitative $\mathrm{CT}$ analysis}

Morphological CT-scan data are shown in Table 4. A significant increase in the fraction of normally aerated areas in parallel with a decrease in collapsed regions $(P=0.008)$ was observed after $24 \mathrm{~h}$ with OLC compared with the first $24 \mathrm{~h}$ with the ARDSnet protocol. No significant changes in aeration were observed in the ARDSnet- $48 \mathrm{~h}$ group when compared with the first $24 \mathrm{~h}$ with ARDSnet.
Comparing the OLC group with the ARDSnet-48 h group, a higher fraction of normally aerated $(P=0.015)$, with a lower fraction of collapsed regions $(P=0.018)$, was observed. No significant difference in hyperinflated regions was observed $(P=0.179)$ among groups.

The distribution of voxels per HU in each protocol is presented in Fig. 2. The OLC (Fig. 2, upper right panel) exhibited a unimodal distribution with a peak in the normally aerated compartment, whereas the histograms of the ARDSnet group exhibited a bimodal pattern with two peaks, one in the normally-aerated and the other in the non-aerated compartment after 24 (Fig. 2, left panel) and $48 \mathrm{~h}$ (Fig. 2, lower right panel) of mechanical ventilation.

Representative 3D reconstructions with the respective histograms of voxels distribution of two patients are

Table 4 Quantitative CT analysis

\begin{tabular}{|c|c|c|c|c|}
\hline & \multicolumn{2}{|c|}{ ARDSnet + OLC $(n=9)$} & \multicolumn{2}{|c|}{ ARDSnet-48h $(n=6)$} \\
\hline & ARDSnet-24h & ARDSnet + OLC & ARDSnet-24h & ARDSnet + OLC \\
\hline Hyper Mass (\%) & $0(0-1)$ & $10-2)$ & $0(0-0.5)$ & $0(0-0.5)$ \\
\hline Norm Mass (\%) & $20(13-22.5)$ & $38^{\mathrm{a}}(31-42)$ & $26.5(15-35)$ & $25(20-39)$ \\
\hline Poorly-aerated Mass (\%) & $25(18-32)$ & $25(18-42)$ & $17(14-21)$ & $16.5(14-20)$ \\
\hline Non-aerated Mass (\%) & $58(51-60)$ & $30^{a}(23-49)$ & $58(47-68)$ & $60.5(43-65)$ \\
\hline Hyper Volume (\%) & $2(0-7)$ & $5(1-14)$ & $0(0-4)$ & $0(0-2)$ \\
\hline Norm Volume (\%) & $41(31-47)$ & $61^{\mathrm{a}}(53-63)$ & $52(36-63)$ & $52.5(41-66)$ \\
\hline Poorly aerated Volume (\%) & $21(15-30)$ & $14(11-29)$ & $14(10-16)$ & $12.5(11-16)$ \\
\hline Non-aerated Volume (\%) & $37(31-41)$ & $13^{\mathrm{a}}(11-23)$ & $33(24-48)$ & $35(20-44)$ \\
\hline
\end{tabular}

Hyper Mass, fraction of non-air content in the hyperinflated compartment related to the total lung mass; Norm Mass, fraction of non-air content in the normally aerated compartment related to the total lung mass

Poorly-aerated Mass fraction of non-air content in the poorly aerated compartment related to the total lung mass, Non-aerated Mass fraction of non-air content in the non aerated compartment related to the total lung mass. Data is presented as median, first and third quartiles

${ }^{\mathrm{a}}$ Significant differences compared to ARDSnet-24h 


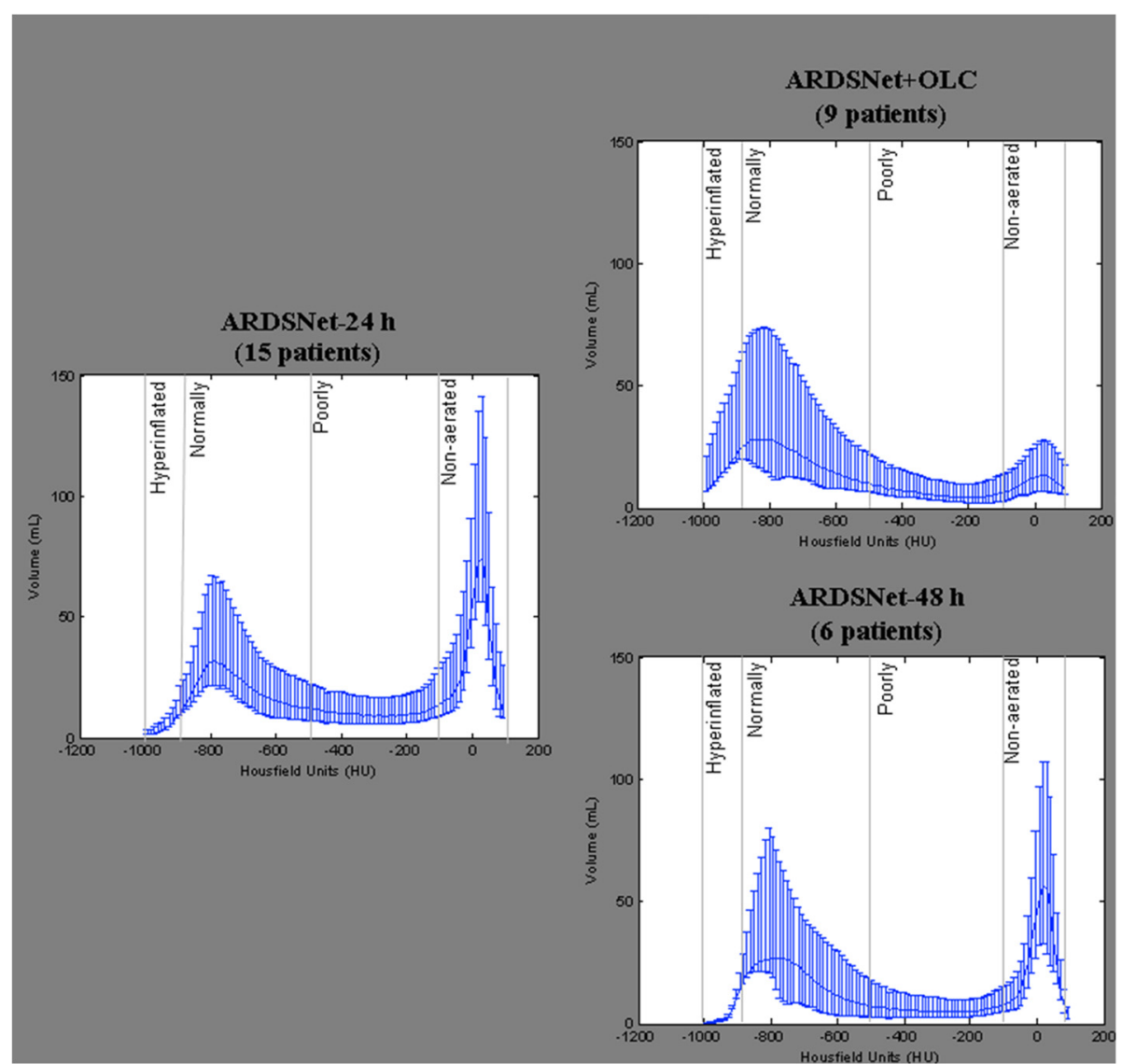

Fig. 2 Histograms of the distribution of aeration (in Hounsfield Units $(H U)$ ) in patients ventilated with the ARDSnetwork protocol during the first $24 \mathrm{~h}$ (left hand panel) followed by ventilation using either the OLC protocol (right hand upper panel) or the ARDSnetwork protocol (right hand lower panel) for the next $24 \mathrm{~h}$. The histograms are presented as the median, first and third quartiles

shown in Figs. 3 and 4. A predominance of collapsed areas can be observed (coloured in black) in the dorsal regions during ARDSnet-24 h (Figs. 3 and 4 upper left panels). Furthermore, the bimodal pattern persisted after $48 \mathrm{~h}$ of mechanical ventilation with the ARDSnet protocol (Fig. 3, right panel), whereas the OLC resulted in a shift from non to normally aerated regions (Fig. 4, right panel).

\section{Cytokine analysis}

Plasma concentrations of IL- 6 decreased after $24 \mathrm{~h}$ of mechanical ventilation with OLC compared with Baseline $(P=0.02)$ and ARDSnet $24 \mathrm{~h}(P=0,005$ - Fig. 5). No significant difference was observed in IL-8 plasma concentration measurements.

\section{Discussion}

The main findings of the present study were: 1) a sustained improvement in oxygenation with a reduction in non and poorly aerated areas was observed after $24 \mathrm{~h}$ of mechanical ventilation with the OLC; 2) no significant increase in driving or plateau pressures, hyperinflated areas or cytokine levels occurred with OLC.

The hazardous effects of ventilation with high volumes are well known [15, 19]. Since the ARDSnet trial [2], protective ventilation with low tidal volume and limited plateau pressure has been the standard of care for patients with ALI/ARDS [3, 20]. Although the concept of atelectrauma is also well established, strategies for its prevention (high levels of PEEP and RMs) are still under debate [21]. Some studies [8-10] failed to show a reduction in mortality with the adoption of high levels of PEEP; however, in two of these $[9,10]$, high PEEP led to a reduction in the incidence of severe hypoxemia that required rescue therapy. In this context, this study was designed to explore the pathophysiological effects of OLC in comparison with a more conservative protective ventilatory strategy, aiming to evaluate the prolonged longitudinal conjoint effects on pulmonary aeration and cytokines.

Regarding oxygenation and respiratory system mechanical properties, there was a sustained improvement in 

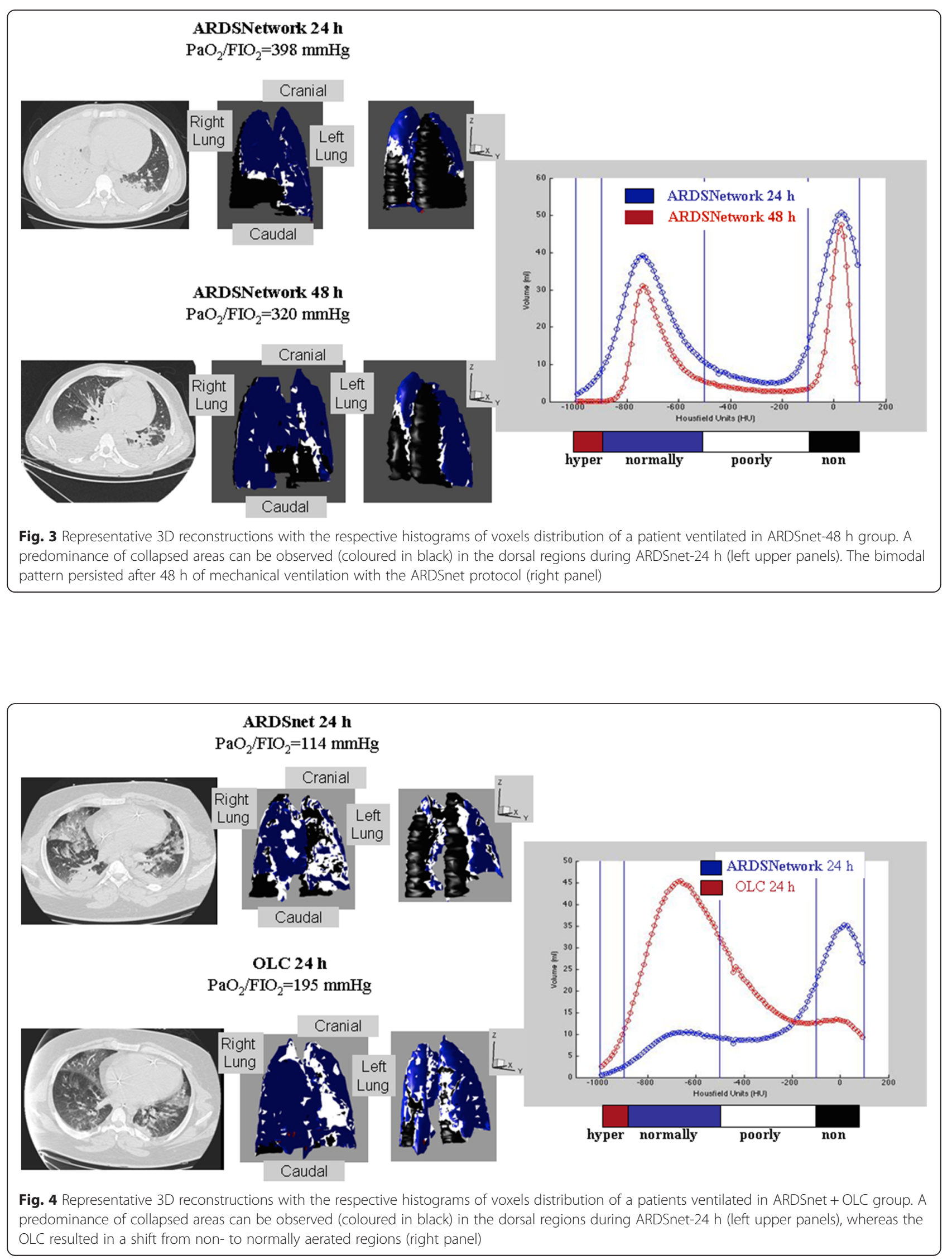


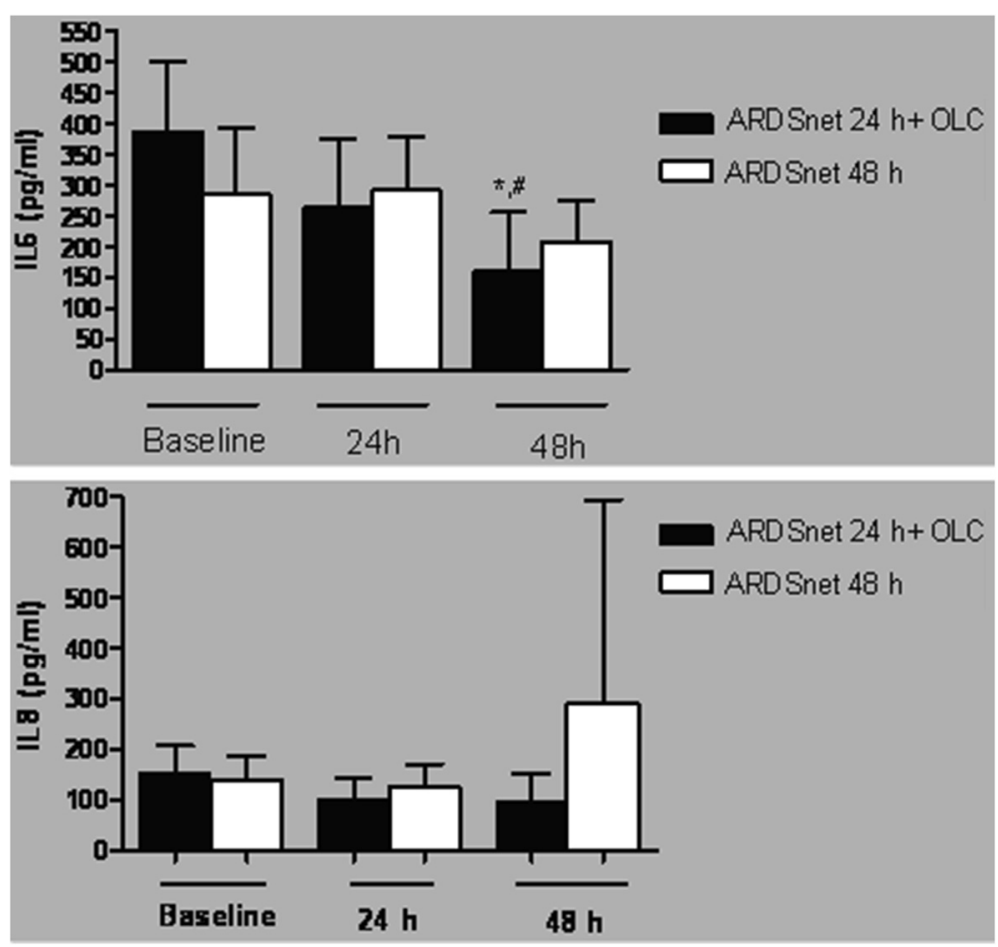

Fig. 5 Plasma concentrations of IL-6 and IL-8 during the protocol. Plasma concentrations of IL-6 decreased after $24 \mathrm{~h}$ of mechanical ventilation with OLC compared with both Baseline $(P=0.02)$ and $24 \mathrm{~h}$ of ARDSnetwork $(P=0,005)$. No significant difference was observed in IL-8 among groups

oxygenation after $24 \mathrm{~h}$ of ventilation with the OLC, as well as an increase in respiratory system compliance in agreement with previous results [10]. The benefits of RMs and high PEEPs may depend on lung recruitability, which may be highly variable [11]. It has been recently shown that higher levels of PEEP improved survival only in patients with severe ARDS [22]. The majority of our patients had just mild ARDS [14]. Despite this, we found a significant reduction in non and poorly aerated areas, without significant increase in hyperinflated areas, plateau and driving pressures. Thus, we believe that our favorable results are a consequence of the adoption of effective RMs. Indeed, the few clinical studies that used maximal recruitment in combination with open-lung PEEP resulted in significant and sustained improvements in oxygenation, as well as in lung mechanics $[9,10]$, and in other studies, there was even a reduction in mortality $[5,23]$. There is a close interdependence between recruitment and PEEP effects. Without an effective RM, the actual open-lung PEEP is difficult to assess [24, 25].

In the current study, maximal pressure levels higher than $40 \mathrm{cmH}_{2} \mathrm{O}$ were applied during the RMs, which appears to be necessary to open the more dependent areas of the lung [16]. The use of a PEEP that keeps $\mathrm{PaO}_{2} / \mathrm{FIO}_{2}$ ratio higher than $350 \mathrm{mmH}_{2} \mathrm{O}$ seems to result in less than five percent of the collapsed areas [16].
In our study, RMs with high pressures were not associated with deleterious hemodynamic effects. This was associated with the inclusion of patients with early ALI/ ARDS who have less stiff chest walls and higher recruitment potentials $[11,19]$.

As previously reported [26], RM with high airway pressures have the potential to induce overdistension leading to an increased production of inflammatory cytokines from different cells in the alveolus and pulmonary vasculature. Nevertheless, cyclic closing and overdistension, induced by lung units with different time-constants, and ventilation with inadequate PEEP levels are also associated with higher levels of cytokines in the alveolar space and blood [27, 28]. In the present study, plasma cytokine concentrations were measured at baseline, 24 and $48 \mathrm{~h}$ after patient inclusion. Despite the use of higher and more sustained pressure inflation in our RM protocol compared to other trials, we found significantly lower plasma levels of IL-6 in the OLC group when compared with the Baseline and $24 \mathrm{~h}$ time points of the ARDSnet. These results are in accordance with CT analysis, where OLC was associated with reduction in non and poorly aerated areas without significant hyperinflation.

The sequential approach adopted in the OLC group suggests the possibility that the progressive fall in 
plasma IL-6 levels may have resulted as a consequence of an improvement in clinical status. To evaluate this possibility, we analyzed a second group, which was ventilated for $48 \mathrm{~h}$ in the ARDSnet protocol (ARDSnet$48 \mathrm{~h}$ ), but we did not find significant changes in cytokine levels (Fig. 5).

The study has limitations. First, it had a small sample size as it was designed to evaluate physiological variables. Second, it was done during $48 \mathrm{~h}$, so inferences regarding clinical outcomes and security cannot be made after this period. Also, as it was a $48 \mathrm{~h}$ study, we could not assure that spontaneous breaths were not present all the time, and if so, probably it would be present more often during ventilation with higher PEEP levels and could interfere with the results in the OLC group. It is also important to emphasize that comparisons between the final results of the two groups (ARDSnet + OLC and ARDSnet-48 h) should be done with caution as patients with worse $\mathrm{PaO}_{2} / \mathrm{FIO}_{2}$ ratios were allocated in the ARDSnet + OLC group, maybe supporting the differences in the results favoring this group.

In summary, our data suggest that the OLC provides an effective approach to reduce the fraction of collapsed tissue without significantly increasing the fraction of hyperinflated tissue and without increasing plasma cytokine levels. We believe that this strategy could provide a viable alternative treatment option for patients with ALI/ARDS. Further studies are warranted to confirm our results and to identify subgroups of patients that will benefit the most from this strategy.

\section{Conclusions}

Mechanical ventilation based on an OLC, applying an individually tailored PEEP, can induce sustained improvement in pulmonary function, with better pulmonary aeration and less hyperinflated areas, without increment in cytokines.

\section{Abbreviations}

Apache, acute physiology and chronic health evaluation II score; ARDS, early acute respiratory distress syndrome; ARDSnet, ARDS network; CT, computed tomography; HU, hounsfield units; I:E, inspiratory to expiratory ratio; IBW, ideal body weight; IL, interleukins; IRB, The hospital Institutional review board; MAP, mean arterial pressure ; OLC, open lung concept protocol; $\mathrm{PaCO}_{2}$, arterial pressure of carbon dioxide; $\mathrm{PaO} 2 / \mathrm{FIO} 2$, arterial pressure of oxygen/inspiratory fraction of oxygen ratio; PCV, pressure controlled ventilation; PEEP, positive end-expiratory pressure; RM, Recruitment maneuver; ROI, region of interest; RR, respiratory rate; SOFA, sequential organ failure assessment; $V_{T}$, tidal volume
}

\section{Acknowledgements}

The authors wish to thank all the staff at critical care units of Copa D'Or Hospital for the support to this ressearch.

\section{Funding}

The authors declare that they received no funding for their research.

\section{Authors' contributions}

Dr VR: contributed to study concept and design, acquisition of data, analysis and interpretation of data, statistical analysis, critical revision of the manuscript for important intellectual content, and drafting of the manuscript. Dr ARC: contributed to study concept and design, acquisition of data, analysis and interpretation of data, statistical analysis, critical revision of the manuscript for important intellectual content, and drafting of the manuscript. Dr RSR: contributed to study concept and design, acquisition of data, analysis and interpretation of data, statistical analysis, critical revision of the manuscript for important intellectual content, and drafting of the manuscript. Dr DMM: contributed to acquisition of data, analysis and interpretation of data, statistical analysis, and drafting of the manuscript. Dr ECP: contributed to acquisition of data, analysis and interpretation of data, statistical analysis, and drafting of the manuscript. Dr FAB: contributed to study concept and design, acquisition of data, analysis and interpretation of data, statistical analysis, critical revision of the manuscript for important intellectual content, and drafting of the manuscript. Dr CRRC: contributed to study concept and design, acquisition of data, analysis and interpretation of data, statistical analysis, critical revision of the manuscript for important intellectual content, and drafting of the manuscript. All authors read and approved the final manuscript.

\section{Competing interests}

The authors declare that they have no competing interests.

\section{Consent for publication}

Written informed consent included the permission to publish indirect identifiers and was obtained from all patients or next-of-kin relatives.

\section{Ethics approval and consent to participate}

The study protocol was approved by the Institutional Review Board (IRB) of Copa D'Or Hospital (number: HCB027/05). Written informed consent was obtained from all patients or next-of-kin relatives.

\section{Author details}

'Internal Medicine Department, Federal University of Rio de Janeiro, Rua Reseda, 23/401, Rio de Janeiro 22471-230, Brazil. "Laboratory of Respiration Physiology, Instituto de Biofísica Carlos Chagas Filho, Federal University of Rio de Janeiro, Rio de Janeiro, Brazil. ${ }^{3}$ Department of Radiology, Federal University of Rio de Janeiro, Rio de Janeiro, Brazil. ${ }^{4} D^{\prime}$ Or Institute for Research and Education (IDOR), Rio de Janeiro, Brazil. ${ }^{5}$ Instituto de Pesquisa Clínica Evandro Chagas (IPEC), Oswaldo Cruz Foundation, Rio de Janeiro, Brazil. " ${ }^{6} \mathrm{CU}$, Copa D'Or Hospital, Rio de Janeiro, Brazil. ${ }^{7}$ Respiratory ICU, InCor-Hospital das Clinicas, University of Sao Paulo, Sao Paulo, Brazil.

Received: 23 March 2015 Accepted: 21 June 2016

Published online: 20 July 2016

\section{References}

1. Lassen HC. A preliminary report on the 1952 epidemic of poliomyelitis in Copenhagen with special reference to the treatment of acute respiratory insufficiency. Lancet. 1953;1:37-41.

2. ARDSnet. Ventilation with lower tidal volumes as compared with traditional tidal volumes for acute lung injury and the acute respiratory distress syndrome. The acute respiratory distress syndrome network. New Engl J Med. 2000;342: 1301-8

3. Slutsky AS, Ranieri VM. Mechanical ventilation: lessons from the ARDSnet trial. Respir Res. 2000;1:73-7.

4. Priolet B, Robert D. Questions about ARDSnetwork trial of low tidal volume. Am J Respir Crit Care Med. 2003;167:1717-8

5. Villar J, Kacmarek RM, Perez-Mendez L, Guirre-Jaime A. A high positive end-expiratory pressure, low tidal volume ventilatory strategy improves outcome in persistent acute respiratory distress syndrome: a randomized, controlled trial. Crit Care Med. 2006;34:1311-8.

6. Gattinoni L, Caironi P. Refining ventilatory treatment for acute lung injury and acute respiratory distress syndrome. JAMA. 2008;299:691-3.

7. Gattinoni L, Carlesso E, Brazzi L, Caironi P. Positive end-expiratory pressure Curr Opin Crit Care. 2010;16:39-44.

8. Brower RG, Lanken PN, Maclntyre N, Matthay MA, Morris A, Ancukiewicz M, et al. Higher versus lower positive end-expiratory pressures in patients with the acute respiratory distress syndrome. N Engl J Med. 2004;351:327-36.

9. Meade MO, Cook DJ, Guyatt GH, Slutsky AS, Arabi YM, Cooper DJ, et al. Ventilation strategy using low tidal volumes, recruitment maneuvers, and 
high positive end-expiratory pressure for acute lung injury and acute respiratory distress syndrome: a randomized controlled trial. JAMA. 2008;299:637-45.

10. Mercat A, Richard JC, Vielle B, Jaber S, Osman D, Diehl JL, et al. Positive end-expiratory pressure setting in adults with acute lung injury and acute respiratory distress syndrome: a randomized controlled trial. JAMA. 2008;299:646-55.

11. Constantin JM, Grasso S, Chanques G, Aufort S, Futier E, Sebbane M, et al. Lung morphology predicts response to recruitment maneuver in patients with acute respiratory distress syndrome. Crit Care Med. 2010;38:1108-17.

12. De Matos GF, Stanzani F, Passos RH, Fontana MF, Albaladejo R, et al. How large is the lung recruitability in early acute respiratory distress syndrome: a prospective case series of patients monitored by computed tomography. Crit Care. 2012;16(1):R4.

13. Ranieri VM, Suter PM, Tortorella C, De Tullio R, Dayer JM, Brienza A, et al: Effect of mechanical ventilation on inflammatory mediators in patients with acute respiratory distress syndrome: a randomized controlled trial. JAMA. 1999;282:54-61.

14. The ARDS. Definition task force. Acute Respiratory Distress Syndrome. The Berlin definition. JAMA. 2012;307:2526-33.

15. Villar J, Perez-Mendez L, Lopez J, Belda J, Blanco J, Saralegui I, et al. An early PEEP/FIO2 trial identifies different degrees of lung injury in patients with acute respiratory distress syndrome. Am J Respir Crit Care Med. 2007;176: 795-804.

16. Borges JB, Okamoto VN, Matos GF, Caramez MP, Arantes PR, Barros F, et al. Reversibility of lung collapse and hypoxemia in early acute respiratory distress syndrome. Am J Respir Crit Care Med. 2006;174:268-78.

17. Gattinoni L, Caironi P, Pelosi P, Goodman LR. What has computed tomography taught us about the acute respiratory distress syndrome? Am J Respir Crit Care Med. 2001;164:1701-11.

18. Carvalho AR, Jandre FC, Pino AV, Bozza FA, Salluh J, Rodrigues R, et al. Positive end-expiratory pressure at minimal respiratory elastance represents the best compromise between mechanical stress and lung aeration in oleic acid induced lung injury. Critical Care (London, England). 2007;11:R86.

19. Imai Y, Parodo J, Kajikawa O, de Perrot M, Fischer S, Edwards V, et al. Injurious mechanical ventilation and end-organ epithelial cell apoptosis and organ dysfunction in an experimental model of acute respiratory distress syndrome. JAMA. 2003;289:2104-12.

20. Grasso S, Stripoli T, De Michele M, Bruno F, Moschetta M, Angelelli G, et al. ARDSnet ventilatory protocol and alveolar hyperinflation: role of positive end-expiratory pressure. Am J Respir Crit Care Med. 2007;176:761-7.

21. Rubenfeld GD. How much PEEP in acute lung injury? JAMA. 2010;303:883-4.

22. Briel M, Meade M, Mercat A, Brower RG, Talmor D, Walter SD, et al. Higher vs lower positive end-expiratory pressure in patients with acute lung injury and acute respiratory distress syndrome: systematic review and metaanalysis. JAMA. 2010;303:865-73.

23. Amato MB, Barbas CS, Medeiros DM, Magaldi RB, Schettino GP, Lorenzi-Filho G, et al. Effect of a protective-ventilation strategy on mortality in the acute respiratory distress syndrome. New Engl J Med. 1998;338:347-54.

24. Suarez-Sipmann F, Bohm SH. Recruit the lung before titrating the right positive end-expiratory pressure to protect it. Critical Care (London, England). 2009;13:134. doi:10.1186/cc7763.

25. Terragni PP, Rosboch G, Tealdi A, Corno E, Menaldo E, Davini O, et al. Tidal hyperinflation during low tidal volume ventilation in acute respiratory distress syndrome. Am J Respir Crit Care Med. 2007;175:160-6.

26. Kacmarek RM, Kallet RH. Respiratory controversies in the critical care settings. Should recruitment maneuvers be used in the in the management of ALI and ARDS? Respir Care. 2007;52:622-31.

27. Iba T, Maitz S, Furbert T, Rosales O, Widmann MD, Spillane B, et al. Effect of cyclic stretch on endothelial cells from different vascular beds. Circ Shock. 1991;35:193-8.

28. Vlahakis NE, Schroeder MA, Limper AH, Hubmayr RD. Stretch induces cytokine release by alveolar epithelial cells in vitro. Am J Physiol. 1999;277:L167-73.

\section{Submit your next manuscript to BioMed Central and we will help you at every step:}

- We accept pre-submission inquiries

- Our selector tool helps you to find the most relevant journal

- We provide round the clock customer support

- Convenient online submission

- Thorough peer review

- Inclusion in PubMed and all major indexing services

- Maximum visibility for your research

Submit your manuscript at www.biomedcentral.com/submit

) Biomed Central 